\title{
Ships may encounter high wind loads—a statistical assessment
}

\section{W Blendermann}

Technical University of Hamburg-Harburg, AB 3-13, Laemmersieth 90, Hamburg D 22305, Germany

\begin{abstract}
The wind loads on ships are treated under long-term wind conditions. Probabilities of high forces and moments are given. A probabilistic criterion for wind heeling levers is proposed.
\end{abstract}

Keywords: ship aerodynamics, wind loading, probability

\section{INTRODUCTION}

Safety and reliable design of ships require risk analysis of their behaviour in the ocean environment. Whereas the probabilistic determination of the wave effects on ships is well established, the assessment of wind loads is still deterministic in codes of practice. For instance, in the International Maritime Organisation (IMO) Code on Intact Stability [1], a bulk wind pressure of $504 \mathrm{~Pa}$ is assumed, independent of the region of voyage, for the stability relevant wind heeling moment on passenger and cargo ships $24 \mathrm{~m}$ in length and over. Trailing back the wind speed, this value seems to be based on a beam wind of about $26 \mathrm{~m} / \mathrm{s}$, corresponding to Beaufort 10 . The code considers static and dynamic effects by combining beam wind and rolling.

Owing to modern approaches to fluid dynamic problems, the behaviour and stability of ships in wind and waves can be treated by direct numerical modelling. Vassalos et al. [2], to name a topical report, investigated the intact stability of a cruise liner in a series of numerical tests not only in waves or wind but also in wind and waves. Though the tested vessel failed to satisfy the IMO stability criterion, it seemed to have a considerable stability margin in terms of probability. This shows the currently basic importance of the probability concept.

An attempt to take into consideration the random characteristics of the ocean winds on different timescales from seconds to years was made by the author $[3,4]$. The long-term wind loads on five ships (car carrier,

The MS was received on 20 November 2003 and was accepted after revision for publication on 1 March 2004. container vessel, destroyer, passenger/car ferry, speed boat), representing typical ship forms, have been investigated by Blendermann [5] using wind tunnel test data [6]. In this text results are presented for a passenger/car ferry. Finally a probabilistic criterion for severe wind heeling levers is proposed.

\section{DEFINITION OF WIND FORCES AND MOMENTS}

Wind forces and moments of relevance on a ship are the longitudinal force, $X$, the transverse force, $Y$, the yaw moment, $N$, and the roll moment, $K$ (Fig. 1). They are defined with respect to a coordinate system with its

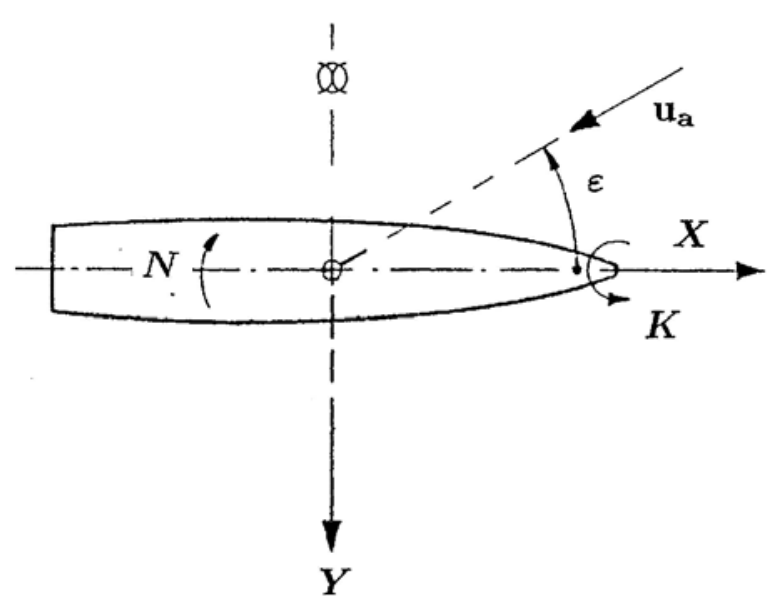

Fig. 1 Coordinate system of wind forces and moments 
origin at the midship section in the waterline plane and are expressed in non-dimensional form as

$$
\begin{aligned}
& c x_{\mathrm{AF}}=\frac{X}{q A_{\mathrm{F}}}, \quad c y=\frac{Y}{q A_{\mathrm{L}}} \\
& c n=\frac{N}{q A_{\mathrm{L}} L_{\mathrm{oa}}}, \quad c k=\frac{K}{q A_{\mathrm{L}} \bar{H}}
\end{aligned}
$$

where $q=(\rho / 2) u_{\mathrm{a}}^{2}$ is the dynamic pressure of the apparent wind, $u_{\mathrm{a}}=$ apparent wind speed, $\rho=$ density of air, $A_{\mathrm{L}}=$ lateral-plane area, $A_{\mathrm{F}}=$ frontal projected area, $L_{\text {oa }}=$ length overall and $\bar{H}=A_{\mathrm{L}} / L_{\mathrm{oa}}=$ mean height.

The apparent wind speed and true wind speed $\boldsymbol{u}$ are related by

$$
\boldsymbol{u}_{\mathrm{a}}=\boldsymbol{u}-\boldsymbol{v}_{\mathrm{s}}
$$

where $\boldsymbol{v}_{\mathrm{s}}$ is the ship speed. Wind load coefficients and data of the ferry are given in Fig. 2, where $\varepsilon$ is the apparent wind angle ( $\varepsilon=0$ in a bow wind $)$.
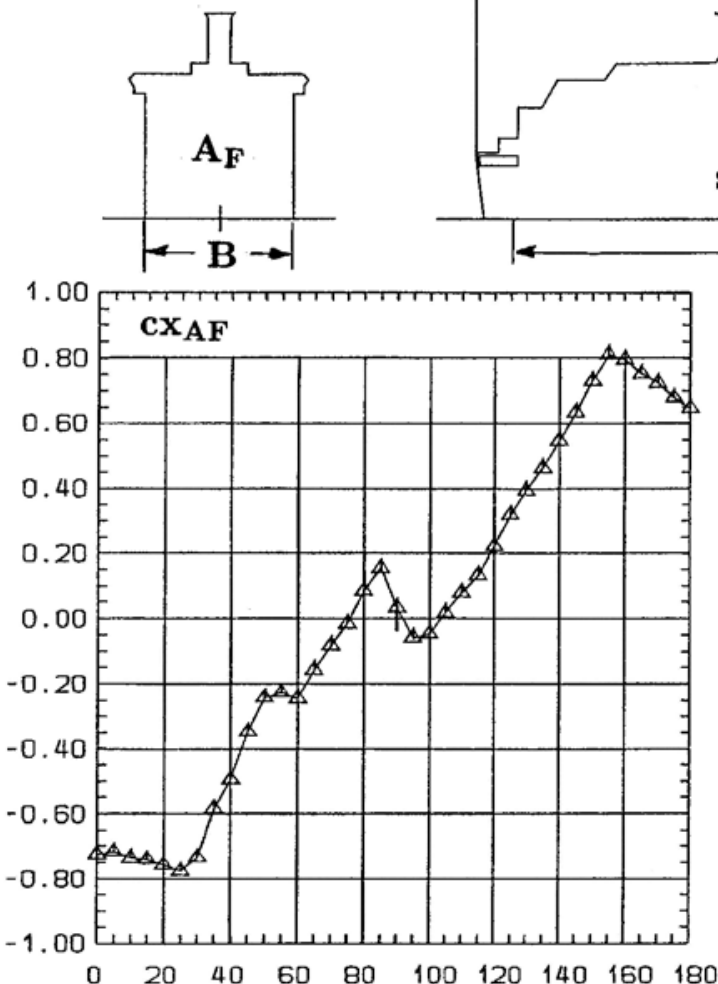

$\varepsilon[\mathrm{deg}]$

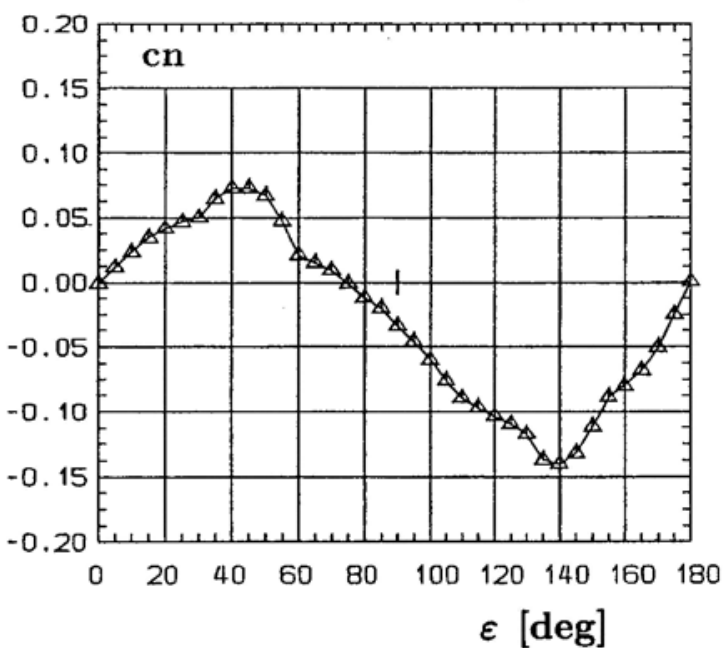

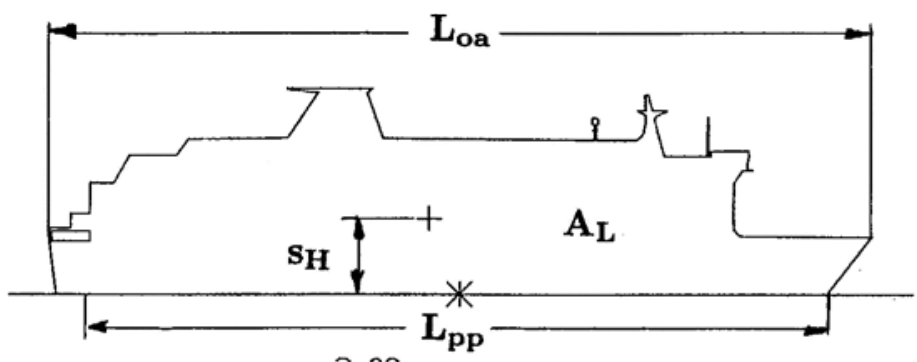
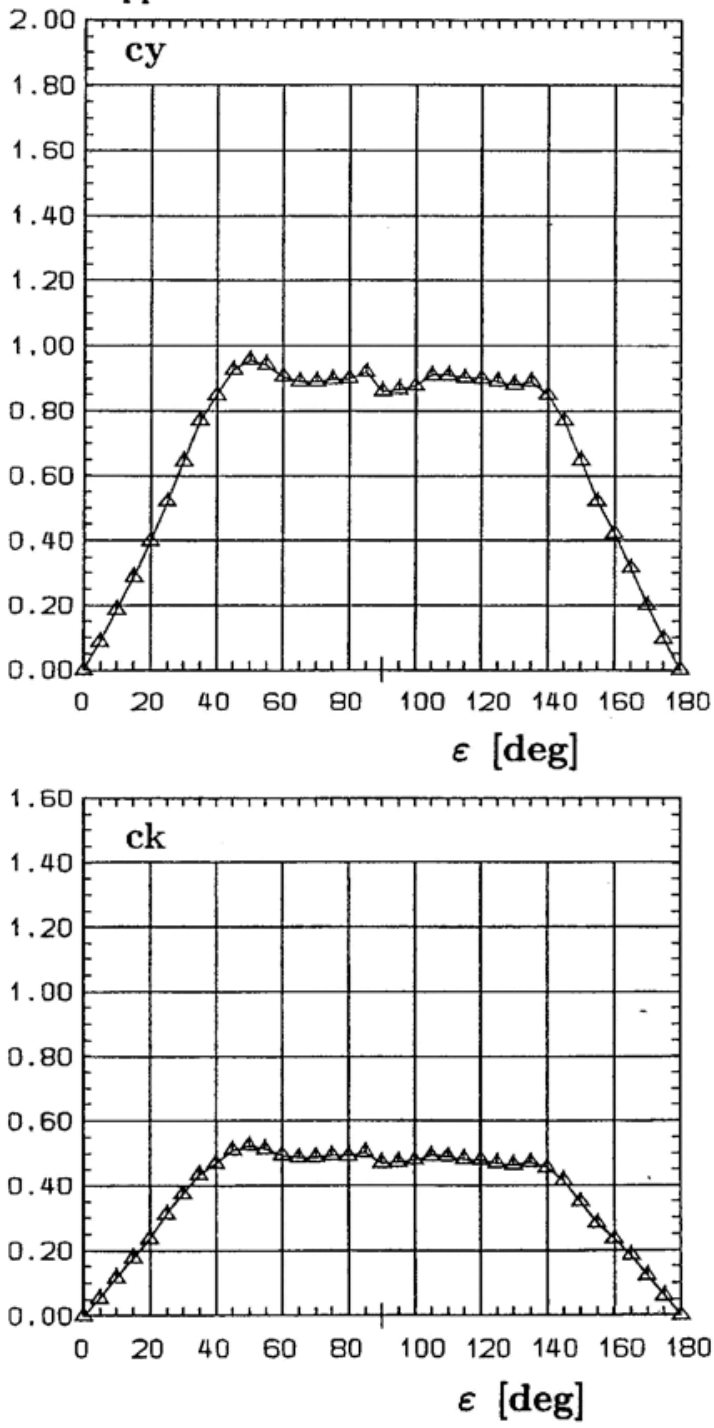

Fig. 2 Wind load coefficients of a passenger $/$ car ferry: $L_{\mathrm{pp}}=144.0 \mathrm{~m}, L_{\mathrm{oa}}=161.0 \mathrm{~m}, B=29.0 \mathrm{~m}, A_{\mathrm{L}}=4223 \mathrm{~m}^{2}$, $A_{\mathrm{F}}=898 \mathrm{~m}^{2}, s_{\mathrm{H}}=14.9 \mathrm{~m} \mathrm{[6]}$ 


\section{WIND STATISTICS}

Young and Holland [7] give data of the hourly average wind speed at $10 \mathrm{~m}$ height above the oceans from satellite measurements over three years. These can be approximated using the Weibull distribution with exponents confined to a narrow range about 2 [8]. Assuming an exponent of 2, the wind speed follows the Rayleigh distribution with density

$$
f(u)=\frac{u}{u_{\text {mode }}^{2}} \exp \left(-\frac{1}{2} \frac{u^{2}}{u_{\text {mode }}^{2}}\right)
$$

Quantity $u_{\text {mode }}$ is the most probable wind speed (modal speed). Instead of $u_{\text {mode }}$, the mean wind speed $E(u)$ (expectation) or the middlemost wind speed $u_{\text {med }}$ (median) may be used. For the Rayleigh distribution these values are related by

$$
u_{\text {mode }}=\sqrt{\frac{2}{\pi}} E(u), \quad u_{\text {mode }}=\frac{1}{\sqrt{2 \ln 2}} u_{\text {med }}
$$

Furthermore, uniform distribution of the true wind angle has been assumed. This should prove adequate where the winds are variable as in the convergence zone of the subtropical and polar air masses (atmospheric polar zone) and may suffice in other regions. The faster a ship with respect to the wind, the closer to the wind it will sail.

\section{LONG-TERM WIND LOAD COEFFICIENTS}

Long-term wind variations are of meteorological origin and are allowed for as fluctuations of the hourly average wind speed. Short-term variations (turbulence, gusts) are aerodynamic effects. The two regimes are distinctly separated from each other in that the spectrum of the wind speed shows a very flat, low gap in the range of periods from $\frac{1}{3}$ hour to about 2 hours [9]. Hence the hourly average wind speed, which is used as the standard wind speed in meteorology, is a very stable quantity. In addition, its definition at $10 \mathrm{~m}$ effective height is standard.

The loads exerted on ships in the long-term regime of the wind primarily concern their extremes. In practice, the probability of certain wind load levels is needed or loads that are not exceeded by a given probability. Suitable quantities are the averages of the highest fraction, $1 / n$, of the loads. They are expressed as nondimensional coefficients of the long-term wind loads: the long-term wind load coefficients, $\overline{C X}_{1 / n}, \overline{C Y}_{1 / n}, \overline{C N}_{1 / n}$ and $\overline{C K}_{1 / n}$, indicate the longitudinal force, the transverse force, the yaw moment and the roll moment respectively. Results for the ferry are shown in Fig. 3. In this figure quantity $r_{X}$ is the probability of wind force ahead (wind $\underline{\text { resistance) }} \underline{\text { and }} r_{N}$ the probability of leeward yaw moment; $\overline{C X}_{1 / n}$ and $\overline{C N}_{1 / n}$ are the respective load coefficients. The wind forces and moments follow from

$$
\begin{aligned}
\bar{X}_{1 / n} & =\overline{C X}_{1 / n} \frac{\rho}{2} u_{\text {mode }}^{2} A_{\mathrm{L}} \\
\bar{Y}_{1 / n} & =\overline{C Y}_{1 / n} \frac{\rho}{2} u_{\text {mode }}^{2} A_{\mathrm{L}} \\
\bar{N}_{1 / n} & =\overline{C N}_{1 / n} \frac{\rho}{2} u_{\text {mode }}^{2} A_{\mathrm{L}} L_{\text {oa }} \\
\bar{K}_{1 / n} & =\overline{C K}_{1 / n} \frac{\rho}{2} u_{\text {mode }}^{2} A_{\mathrm{L}} \bar{H}
\end{aligned}
$$

Roll moment levers are almost independent of the angle of wind attack or do not change much in the relevant range of wind angles about the beam [13]. They can be assumed to be constant over the whole range of wind attack.

The long-term wind load coefficients of Fig. 3 do not account for drift. Drift leads to a reduction especially of the transverse force and the heeling moment. The drift speed of a ship without speed in a beam wind is given by

$$
\frac{v_{\mathrm{drift}}}{u}=\frac{\alpha_{\mathrm{drift}}}{1+\alpha_{\mathrm{drift}}}, \quad \alpha_{\mathrm{drift}}=\sqrt{\frac{\left(\rho c d_{\mathrm{t}} A_{\mathrm{L}}\right)_{\mathrm{o}}}{\left(\rho c d_{\mathrm{t}} A_{\mathrm{L}}\right)_{\mathrm{u}}}}
$$

where $u$ is the momentary mean wind speed and $c d_{\mathrm{t}}=$ lateral drag coefficient. The subscripts o and $\mathrm{u}$ mark data above and below the waterline respectively. Drift speeds of five ships and relative reductions of the transverse force, $1-\left(1-v_{\text {drift }} / u\right)^{2}$, are given in Table 1 .

Figure 4 shows the reduction of the long-term transverse wind force on the ferry due to drift. It decreases rapidly when the ship is under way. The amount of transverse force and heeling moment reductions is the same. The reduction of the longitudinal wind force is negligible. Reduction values of five ships for $n=100$, related to the respective values in the beam wind, have been plotted in Fig. 5. The average reduction for the ships given in Table 2 can be used as a rough guide.

Table 1 Drift speed in the beam wind and relative reduction of the transverse wind force

\begin{tabular}{lll}
\hline Ship without speed & $v_{\text {drift }} / u$ & Relative reduction of $Y$ \\
\hline Car carrier & 0.08 & 0.15 \\
Container ship, laden & 0.06 & 0.12 \\
Destroyer & 0.05 & 0.10 \\
Passenger/car ferry & 0.12 & 0.23 \\
Speed boat & 0.08 & 0.15 \\
\hline
\end{tabular}



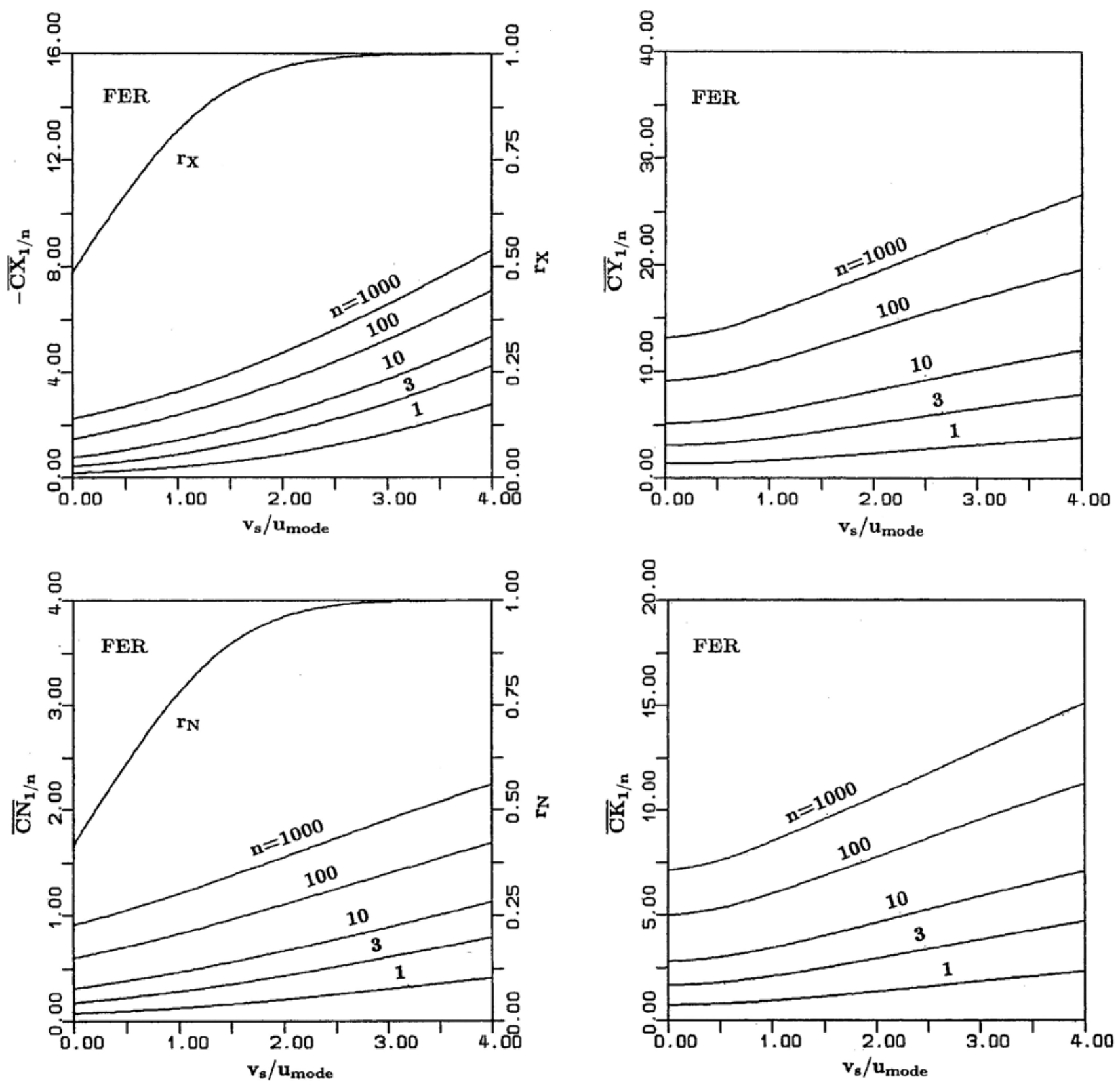

Fig. 3 Coefficients of the long-term average wind loads of the highest fraction $1 / n$ on a passenger/car ferry versus ship speed over modal wind speed; probability of wind force ahead, $r_{\mathrm{X}}$, and of leeward yaw moment, $r_{\mathrm{N}}$

Table 2 Average reduction of the long-term transverse wind force due to drift related to the reduction in the beam wind

\begin{tabular}{llllllllll}
\hline$v_{\mathrm{s}} / u_{\text {mode }}$ & 0.0 & 0.25 & 0.5 & 1.0 & 1.5 & 2.0 & 2.5 & 3.0 & 4.0 \\
\hline$\frac{1-\bar{Y}_{1 / p \text { with drift }} / \bar{Y}_{1 / n \text { without drift }}}{1-\left(1-v_{\text {drift }} / u\right)^{2}}$ & 0.90 & 0.66 & 0.42 & 0.24 & 0.17 & 0.13 & 0.12 & 0.10 & 0.09 \\
\hline
\end{tabular}

\section{Example}

Long-term wind loads on a passenger/car ferry (Fig. 2) in the North Sea during strong-wind season, $L_{\mathrm{oa}}=$ $161.0 \mathrm{~m}, A_{\mathrm{L}}=4223 \mathrm{~m}^{2}$ and $\bar{H}=26.2 \mathrm{~m}$. The ship speed $v_{\mathrm{s}}=20$ knots and the wind speed $u_{\text {mode }}=9.0 \mathrm{~m} / \mathrm{s}$, so $v_{\mathrm{s}} / u_{\text {mode }}=1.1$. With the coefficients from Fig. 2 the averages of the highest fraction $1 / n$ of the wind loads that the vessel may encounter are as given in Fig. 6. The drift speed of the ship in the beam wind is $v_{\text {drift }} / u=0.12$. 


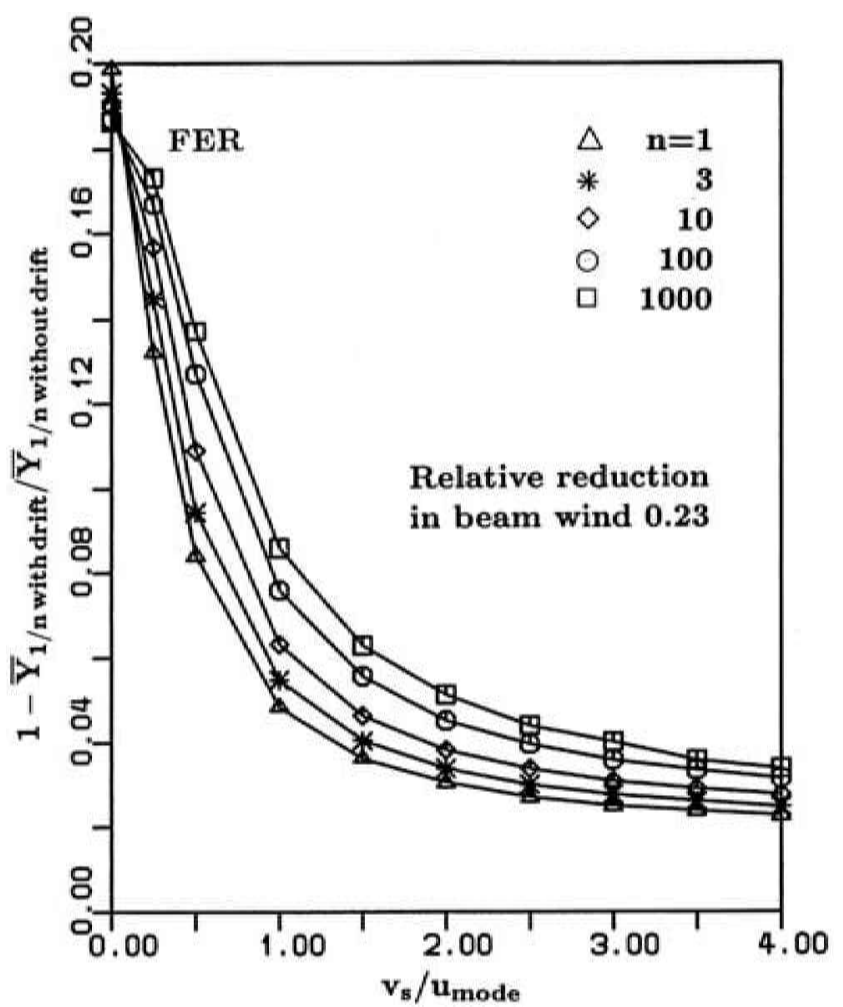

Fig. 4 Relative reduction of the long-term transverse wind force on a passenger/car ferry due to drift

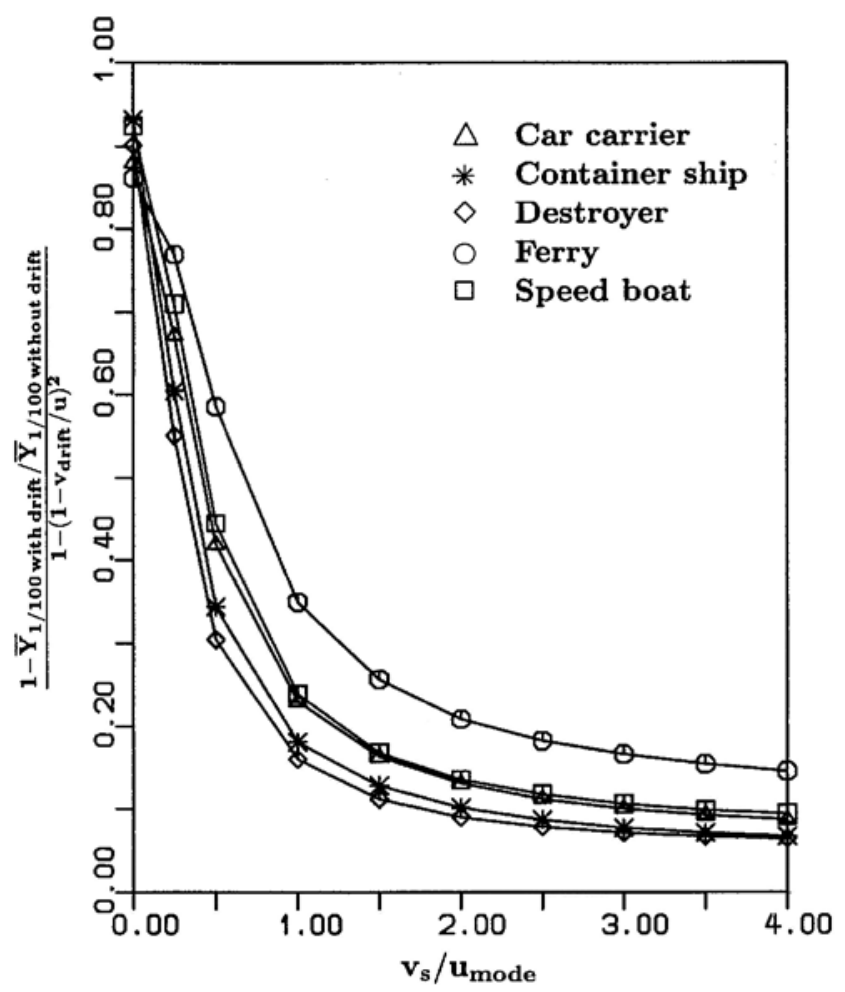

Fig. 5 Reduction of the average transverse wind force of the highest fraction $1 / 100$ due to drift related to the reduction in the beam wind

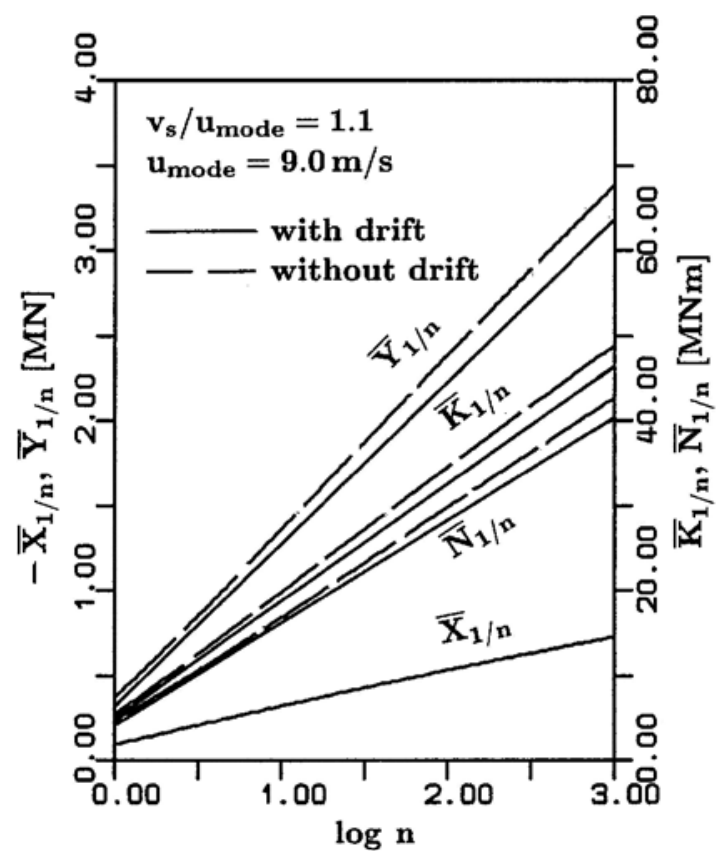

Fig. 6 Average of the highest fraction $1 / n$ of the wind loads on a passenger/car ferry in the North Sea

\section{WIND ABOUT THE BEAM}

Wind heeling levers are adopted in stability criteria. Most critical situations are those when a ship is out of control drifting in wind and waves $\left(v_{\mathrm{s}} / u_{\text {mode }} \simeq 0\right)$. The average transverse force of the highest fraction $1 / n$ can then be approximated by (Fig. 7)

$$
\left(\overline{C Y}_{1 / n}\right)_{v_{\mathrm{S}}=0}=(1+3.0 \log n) E(C Y)_{v_{\mathrm{s}}=0}
$$

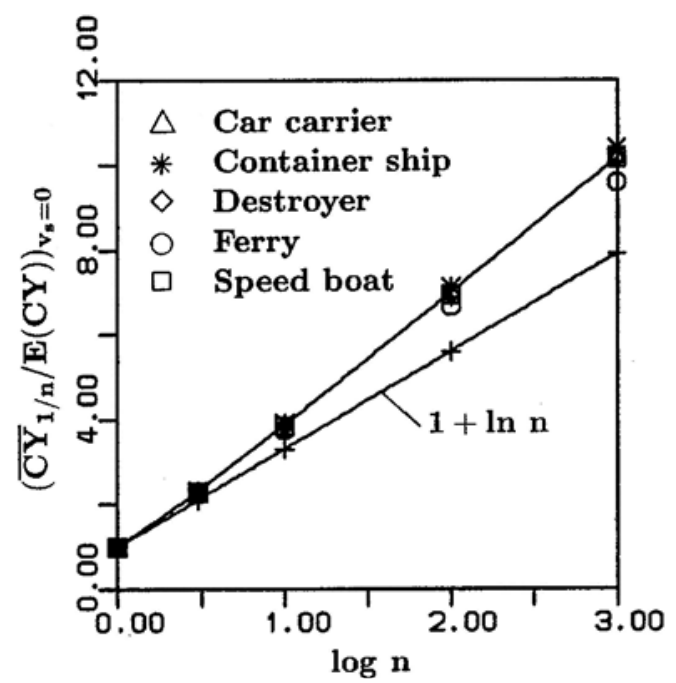

Fig. 7 Average transverse wind force of the highest fraction $1 / n$ over its expectation on a ship without speed, with the respective quantity in wind acting perpendicular to the ship's centre-line (crosses) 
where $\log n=\log _{10} n$ and expectation $E(C Y)$ is the longterm coefficient of the average transverse force $(n=1)$. Further, $E(C Y)_{v_{\mathrm{S}}=0}$ and the angular-mean transverse force coefficient

$$
\overline{c y}=\frac{1}{\pi} \int_{0}^{\pi} c y \mathrm{~d} \varepsilon
$$

are correlated by (Fig. 8)

$$
E(C Y)_{v_{\mathrm{s}}=0}=2.0 \overline{c y}
$$

Quantity $\overline{c y}$ can be written as

$$
\overline{c y}=k_{\mathrm{c}} c d_{\mathrm{t}}
$$

where $c d_{\mathrm{t}}=c y_{\varepsilon=\pi^{2}}$ is the drag coefficient in the beam wind. Average values for $c d_{\mathrm{t}}$ and $k_{\mathrm{c}}$ are given in Table 3 . Quantity $k_{\mathrm{c}}$ depends essentially on the ship type with an average $k_{\mathrm{c}}=0.71$ (Fig. 9). Quantity $\kappa$ in the table is a roll moment factor to be used later.

Thus the average of the highest fraction $1 / n$ of the mean hourly transverse force, without reduction due to

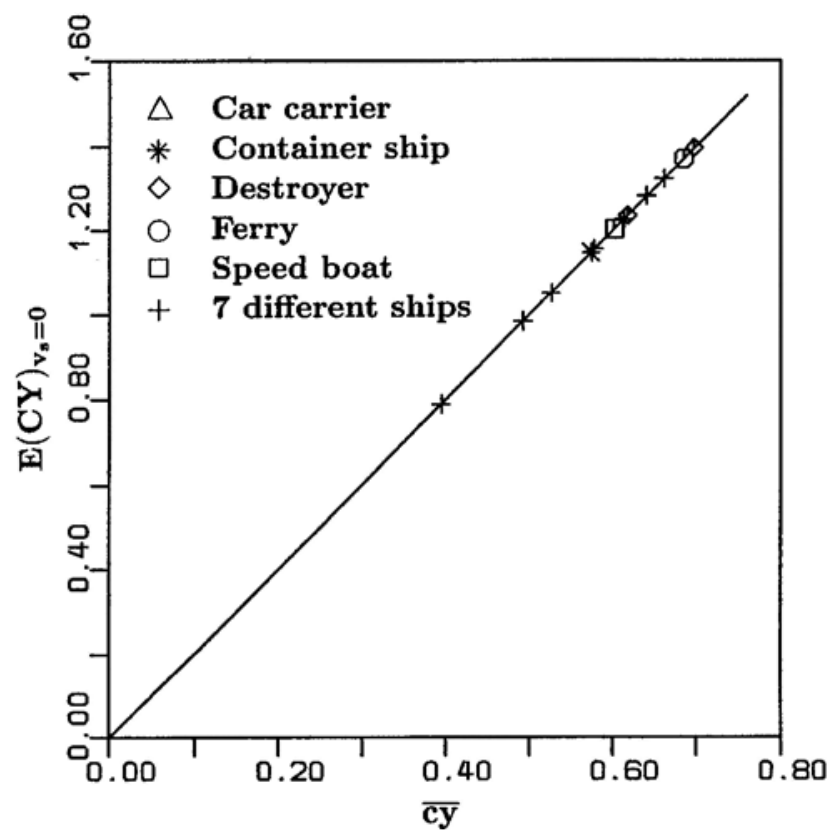

Fig. 8 Correlation of the expectation of the long-term transverse wind force on the ship without speed and the angular-mean transverse force coefficient

Table 3 Drag coefficients and parameters

\begin{tabular}{llll}
\hline Type of vessel & $\begin{array}{l}c d_{\mathrm{t}} \\
\text { beam wind }\end{array}$ & $k_{\mathrm{c}}$ & $\kappa$ \\
\hline Car carrier & 0.95 & 0.75 & 1.2 \\
Container ship, laden & 0.90 & 0.66 & 1.4 \\
Destroyer & 0.85 & 0.73 & 1.1 \\
Passenger/car ferry & 0.90 & 0.79 & 1.1 \\
Speed boat & 0.90 & 0.69 & 1.1 \\
\hline
\end{tabular}

drift, in wind about the beam can be written as

$$
\left(\bar{Y}_{1 / n}\right)_{v_{\mathrm{s}}=0}=2.0 k_{\mathrm{c}}(1+3.0 \log n) c d_{\mathrm{t}} \frac{\rho}{2} u_{\text {mode }}^{2} A_{\mathrm{L}}
$$

When related to $\overline{c y}, \overline{C Y}_{1 / n}$ does not differ or differs only a little for different ships up to $v_{\mathrm{s}} / u_{\text {mode }}$ of about 2 (Fig. 10).

A slightly different result is obtained when the ship is oblique to the wind, so that the wind is acting perpendicular to the ship's centre-line. Assuming as before the Rayleigh distribution of the long-term wind speeds, the wind speed squared follows the exponential distribution

$$
F\left(u^{2}\right)=1-\exp \left(-\frac{1}{2} \frac{u^{2}}{u_{\text {mode }}^{2}}\right)
$$

with density

$$
f\left(u^{2}\right)=\frac{1}{2 u_{\text {mode }}^{2}} \exp \left(-\frac{1}{2} \frac{u^{2}}{u_{\text {mode }}^{2}}\right)
$$

and expectation $E\left(u^{2}\right)=2 u_{\text {mode }}^{2}$. The average of the highest fraction $1 / n$ of $u^{2}$ is

$$
\bar{u}_{1 / n}^{2}=(1+\ln n) E\left(u^{2}\right)
$$

and its probability of exceedance is

$$
P\left(u^{2}>\bar{u}_{1 / n}^{2}\right)=\frac{1}{e} \frac{1}{n}
$$

where $e=2.718=$ base of the natural logarithm.

Under these conditions the average transverse force of the highest fraction $1 / n$ is given by

$$
\left(\bar{Y}_{1 / n}\right)_{v_{\mathrm{s}}=0}=2(1+\ln n) c d_{\mathrm{t}} \frac{\rho}{2} u_{\text {mode }}^{2} A_{\mathrm{L}}
$$

If the maximum $c y>c d_{\mathrm{t}}$, this value should be used instead of $c d_{\mathrm{t}}$ (see Fig. 2). Function $(1+\ln n)$ has been added in Fig. 7. Differences between the forces in wind about the beam (15) and perpendicular to the ship's centre-line (20) are marginal. This is shown in the following example.

\section{Example}

Long-term transverse wind force on a ship at zero speed. The same ship is used as in the first example, with $A_{\mathrm{L}}=4223 \mathrm{~m}^{2}, c d_{\mathrm{t}}=0.86$ and $k_{\mathrm{c}}=0.79$ from Table 3 . The wind speed $u_{\text {mode }}=9.0 \mathrm{~m} / \mathrm{s}$. Results are plotted in Fig. 11.

\section{WIND HEELING LEVERS}

Long-term wind load as defined in this text is an hourly average. Momentary wind load can be understood as the combined result of this static quantity and a dynamic force or moment due to the wind gustiness, i.e. 


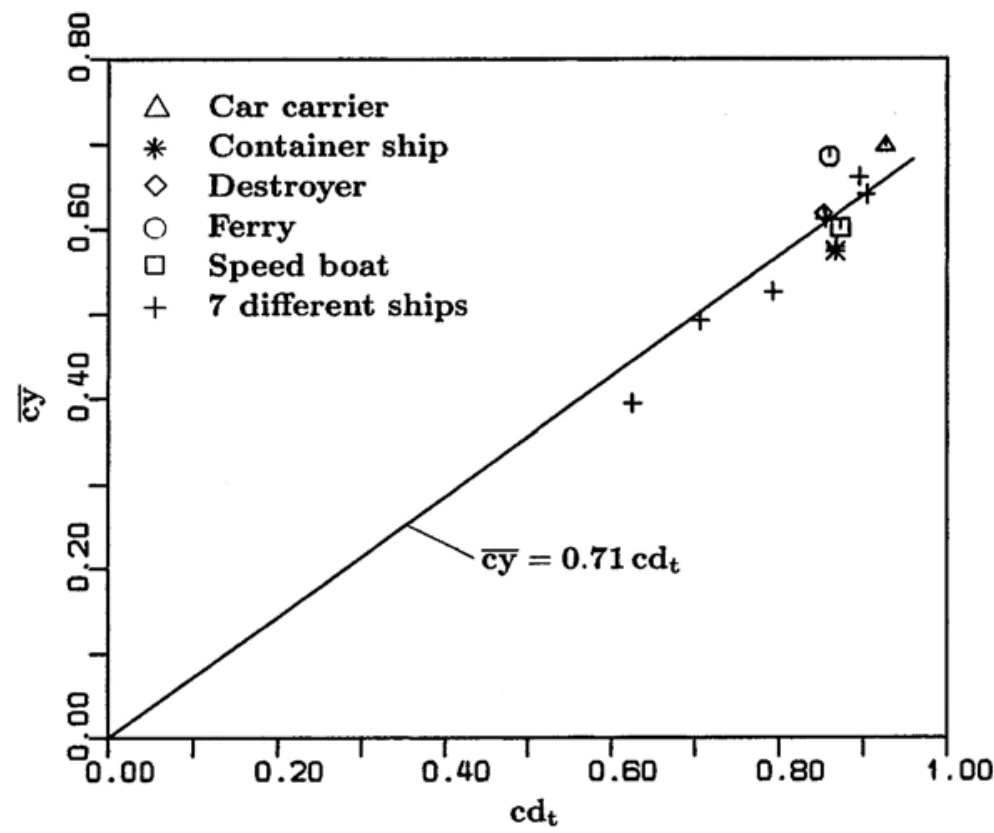

Fig. 9 Correlation of the angular-mean transverse force coefficient and the transverse drag coefficient in the beam wind

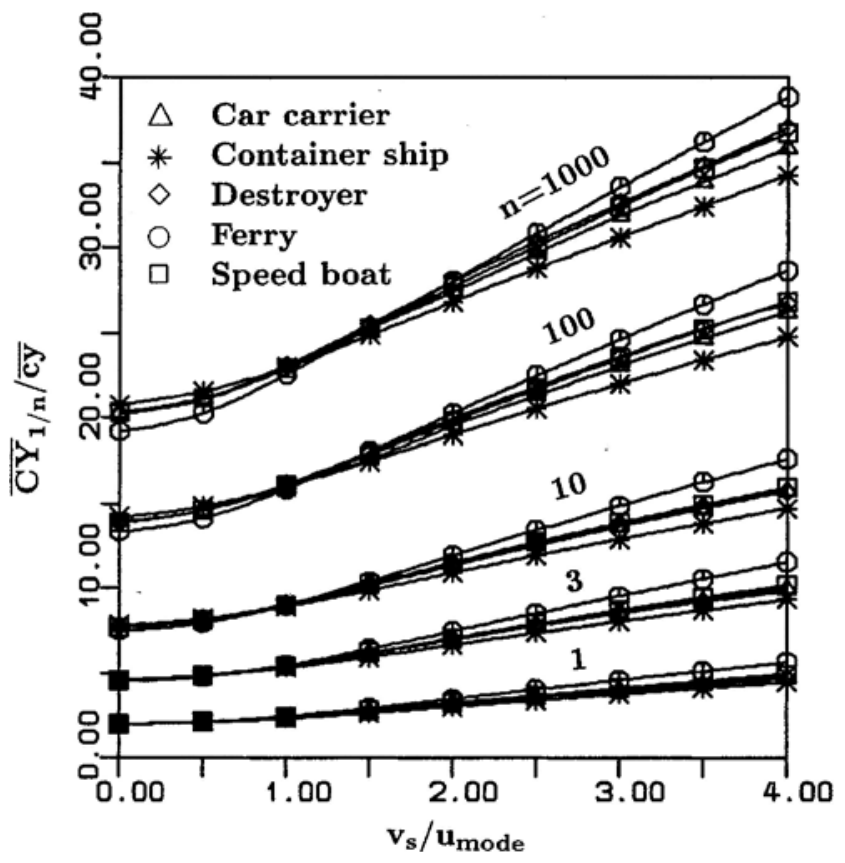

Fig. 10 Coefficient of the long-term transverse wind force of the highest fraction $1 / n$ related to the angular-mean transverse force coefficient

superposition of long-term and short-term wind effects. The following approach is for the transverse force; it is exactly the same for the other load components.

It is convenient to split the momentary wind speed $u(t)$ into the hourly average $\bar{u}$ and a fluctuating part $u^{\prime}(t)$ :

$$
u(t)=\bar{u}+u^{\prime}(t)
$$

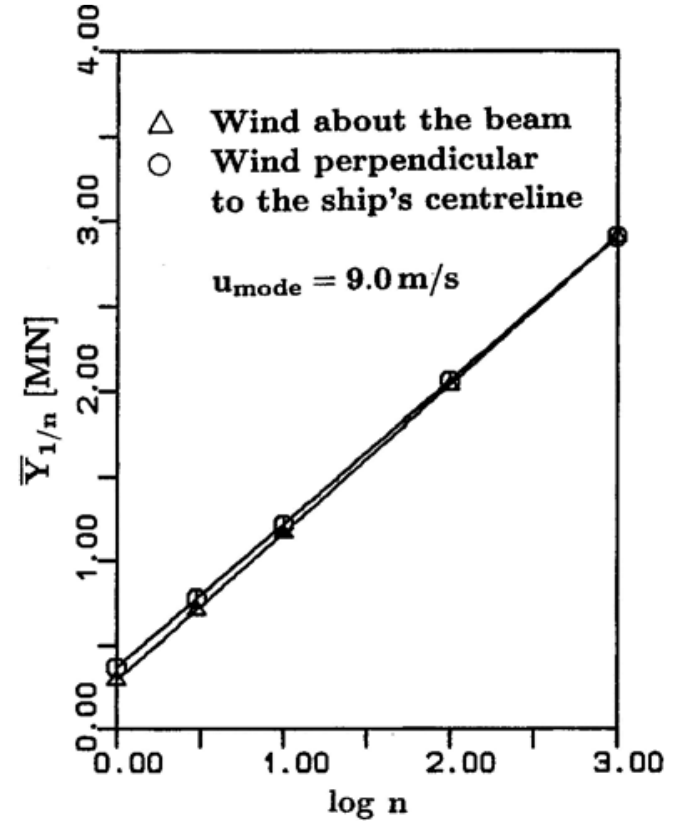

Fig. 11 Average transverse wind force of the highest fraction $1 / n$ on a passenger/car ferry at zero speed in the North Sea

Speed $u^{\prime}(t)$ is the fluctuation in wind direction that is felt as a gust with increasing force of the wind. The most prominent spectrum $S_{\mathrm{u}}(f)$ for $u^{\prime}$ in strong winds of an essentially neutral atmosphere is the Davenport spectrum [10], written in the usual reduced, non-dimensional form

$$
\frac{f S_{\mathrm{u}}(f)}{C_{10} \bar{u}_{10}^{2}}=\frac{4 \tilde{f}^{2}}{\left(1+\tilde{f}^{2}\right)^{4 / 3}}
$$


where $\tilde{f}=f L / \bar{u}_{10}$ is the non-dimensional frequency of the wind fluctuations and $L=1200 \mathrm{~m}$ is a length parameter. Quantity $C_{10}$ is the coefficient of frictional resistance at $10 \mathrm{~m}$ height above ground level. Above the ocean, $C_{10}=\left(0.75+0.067 \bar{u}_{10}\right) \times 10^{-3}$ can be assumed [11]. The frequency of the most energetic gusts (modal frequency) is $\tilde{f}_{\text {mode }}=0.775$, corresponding to a wavelength $\lambda_{\mathrm{u}}=\bar{u} / f$ of $1500 \mathrm{~m}$. The reference wind speed is the hourly average speed at $10 \mathrm{~m}$ height.

Wind turbulence has normal (Gaussian) distribution with density

$$
f\left(u^{\prime}\right)=\frac{1}{\sqrt{2 \pi}} \frac{1}{\sqrt{m_{0 \mathrm{u}}}} \exp \left(-\frac{1}{2} \frac{u^{\prime 2}}{m_{0 \mathrm{u}}}\right)
$$

where $m_{0 \mathrm{u}}$ is the variance or zeroth spectral moment

$$
\begin{aligned}
m_{0 \mathrm{u}} & =\int_{0}^{\infty} S_{\mathrm{u}}(f) \mathrm{d} f=4 C_{10} \bar{u}_{10}^{2} \int_{0}^{\infty} \frac{\tilde{f}^{2}}{\left(1+\tilde{f}^{2}\right)^{4 / 3}} \mathrm{~d} \tilde{f} \\
& =6.0 C_{10} \bar{u}_{10}^{2}
\end{aligned}
$$

As before, the ship is assumed to be unmanageably drifting in the wind. Periods of gusts affecting the ship's behaviour are such that momentary wind loading can be treated as a steady state load (quasi-static calculation). The transverse force in the beam wind is then given by

$$
\begin{aligned}
Y(t) & =c d_{\mathrm{t}} \frac{\rho}{2}\left[\bar{u}+u^{\prime}(t)\right]^{2} A_{\mathrm{L}} \\
& =c d_{\mathrm{t}} \frac{\rho}{2}\left[\bar{u}^{2}+2 \bar{u} u^{\prime}(t)+u^{\prime 2}(t)\right]^{2} A_{\mathrm{L}}
\end{aligned}
$$

Using the standard deviation of the wind turbulence, $\sqrt{m_{0 u}}$, it can be shown that about 90 per cent of the fluctuations are within $\pm 0.15 \bar{u}$. Thus the quadratic term of $u^{\prime}(t)$ can be neglected, so that

$$
Y(t)=c d_{\mathrm{t}} \frac{\rho}{2} \bar{u}^{2} A_{\mathrm{L}}+c d_{\mathrm{t}} \rho \bar{u} u^{\prime}(t) A_{\mathrm{L}}
$$

The first term is the mean load $\bar{Y}$; it causes a steady heeling of the ship. The second, the load fluctuation, may induce roll. It can be written as

$$
Y^{\prime}(t)=2\left(\frac{\bar{Y}}{\bar{u}}\right) u^{\prime}(t)
$$

Thus

$$
Y(t)=\bar{Y}+2\left(\frac{\bar{Y}}{\bar{u}}\right) u^{\prime}(t)
$$

Code relevant wind speeds are maximum averages over short time intervals. The dependence on the averaging time is commonly expressed by

$$
u_{\text {gu st }}=b_{\mathrm{f}}(t, T) u_{\text {basic }}
$$

Quantity $b_{\mathrm{f}}(t, T)$, the gust factor, is the maximum average wind speed over time $t$ divided by the average wind speed over $T$, here 1 hour. Values are given in Table 4.

Applying equation (28) to equation (20), the transverse wind force can be written as

$$
\left(\bar{Y}_{1 / n}\right)_{v_{\mathrm{S}}=0}=Y_{\text {steady }}+2 Y_{\text {steady }}\left(\frac{u_{\text {gust }}}{u_{\text {steady }}}-1\right)
$$

where

$$
Y_{\text {steady }}=c d_{\mathrm{t}} \frac{\rho}{2} u_{\text {steady }}^{2} A_{\mathrm{L}}
$$

and

$$
u_{\text {steady }}=\left(b_{\text {f steady }}-\frac{v_{\text {drift }}}{u}\right) \sqrt{2(1+\ln n)} u_{\text {mode }}
$$

with additional consideration of drift due to the mean wind as given in equation (10). Quantity $b_{\mathrm{f} \mathrm{steady}}$ is the gust factor of $u_{\text {steady }}$. The respective gust factor of $u_{\text {gust }}$ is $b_{\mathrm{f} \text { gust }}$. Together with

$$
\frac{u_{\text {gu st }}}{u_{\text {steady }}}=\frac{b_{\text {f gust }}-v_{\text {drift }} / u}{b_{\text {f steady }}-v_{\text {drift }} / u} \approx \frac{b_{\text {f gust }}}{b_{\text {f steady }}}
$$

equation (30) eventually yields

$$
\left(\bar{Y}_{1 / n}\right)_{v_{\mathrm{S}}=0}=Y_{\text {steady }}+2 Y_{\text {steady }}\left(\frac{b_{\text {f gust }}}{b_{\text {f steady }}}-1\right)
$$

The first term is static, leading to a steady wind heel; the action of the second term is dynamic. It is assumed that relevant gusts affect the whole ship. Design wind speeds recommended by classification societies are the average over 1 minute for the mean wind speed $u_{\text {steady }}$ and the average over 3 seconds for the gust speed $u_{\text {gust }}$ ( 1 minute and 3 second gusts respectively).

The heeling moment about the waterline can be written as

$$
\left(\bar{K}_{1 / n}\right)_{v_{\mathrm{s}}=0}=\kappa s_{\mathrm{H}}\left(\bar{Y}_{1 / n}\right)_{v_{\mathrm{S}}=0}
$$

where $s_{\mathrm{H}}$ is the height of the lateral-plane centre above the waterline (Fig. 2). Quantity $\kappa$ is a roll moment factor

Table 4 Gust factors for the ocean environment [12]

\begin{tabular}{ll}
\hline $\begin{array}{l}\text { Averaging time } \\
t\end{array}$ & $\begin{array}{l}\text { Gust factor } \\
b_{\mathrm{f}}(t, T) \text { for } T=1 \mathrm{~h}\end{array}$ \\
\hline $3 \mathrm{~s}$ & 1.37 \\
$5 \mathrm{~s}$ & 1.34 \\
$10 \mathrm{~s}$ & 1.30 \\
$15 \mathrm{~s}$ & 1.27 \\
$20 \mathrm{~s}$ & 1.25 \\
$30 \mathrm{~s}$ & 1.23 \\
$1 \mathrm{~min}$ & 1.17 \\
$10 \mathrm{~min}$ & 1.04 \\
$1 \mathrm{~h}$ & 1.00 \\
\hline
\end{tabular}


that comprises mainly the contribution of lift forces to the overturning moment. It depends essentially on the ship type (Table 3 ).

Equations (34) and (35) may be used for a probabilistic approach to severe wind heeling moments on ships:

(a) to assess the probability that recommended design heeling levers will not be exceeded in an ocean area or on a shipping route;

(b) to recommend design heeling levers for a region of voyage that will not be exceeded on an acceptable level of probability.

In the IMO Code on Intact Stability [1], a steady wind heeling lever

$$
l_{\mathrm{w} 1}=\frac{p A_{\mathrm{L}} z}{g \Delta}
$$

should be assumed, where $p=504 \mathrm{~N} / \mathrm{m}^{2}=$ wind pressure, $g=9.81 \mathrm{~m} / \mathrm{s}^{2}=$ gravitational acceleration and $\Delta=$ displacement. Quantity $z$ is the vertical distance from the centre of $A_{\mathrm{L}}$ to the centre of the underwater lateral area or approximately to a point at one-half the mean draught. The recommended gust wind heeling lever is

$$
l_{\mathrm{w} 2}=1.5 l_{\mathrm{w} 1}
$$

corresponding to $(1-\sqrt{1.5}) \times 100 \%=22$ per cent increase of the average wind speed of $26 \mathrm{~m} / \mathrm{s}$. Application of equation (36) to equation (34) gives the following longterm average wind heeling levers of the highest fraction $1 / n$ :

$$
\begin{aligned}
& l_{\text {steady }}=\frac{Y_{\text {steady }}\left(\kappa s_{\mathrm{H}}+s_{\mathrm{Hu}}\right)}{g \Delta} \\
& l_{\text {gust }}=\left(2 \frac{b_{\text {f gust }}}{b_{\mathrm{f} \mathrm{steady}}}-1\right) l_{\text {steady }}
\end{aligned}
$$

together with $Y_{\text {steady }}$ from equation (31). Underwater it suffices to assume the lateral-plane centroid as the centre of the reactive force; $s_{\mathrm{Hu}}$ is its distance from the waterline.

\section{Example}

Long-term wind heeling levers of a passenger/car ferry. This is the same ship as in the first example, with zero speed due to a blackout, displacement $\Delta=21000 \mathrm{t}$, lateralplane area above the waterline $A_{\mathrm{L}}=4223 \mathrm{~m}^{2}$, vertical distance of its centre from the waterline $s_{\mathrm{H}}=14.9 \mathrm{~m}$, lateral-plane area below the waterline $960 \mathrm{~m}^{2}$, vertical distance of its centre from the waterline $s_{\mathrm{Hu}}=3.0 \mathrm{~m}$ and wind speed $u_{\text {mode }}=9.0 \mathrm{~m} / \mathrm{s}$. With the data of the vessel the wind heeling levers according to the IMO code are $l_{\mathrm{w} 1}=0.19 \mathrm{~m}$ and $l_{\mathrm{w} 2}=0.29 \mathrm{~m}$. For the vessel $c d_{\mathrm{t}}=0.86$ and, further, $\kappa=1.1$ (Table 3 ). With averaging times of

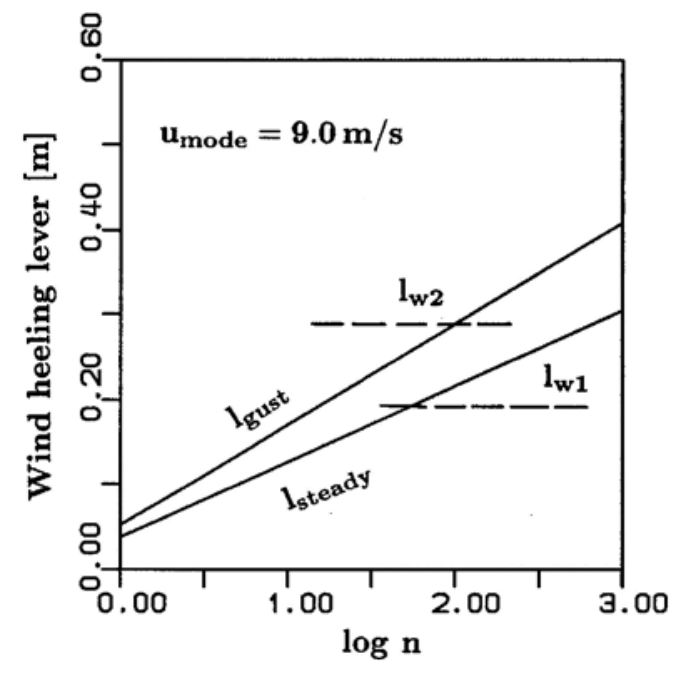

Fig. 12 Long-term average wind heeling levers of the highest fraction $1 / n$ of a passenger/car ferry in the North Sea; IMO recommendations are given for comparison

1 minute for the mean wind and 3 seconds for the gust, the gust factors are 1.17 and 1.37 respectively (Table 4). Thus $l_{\text {gust }}=1.34 l_{\text {steady }}$. The wind heeling levers have been plotted in Fig. 12 and compared with the IMO recommendations. The drift speed of the ship in the beam wind is $v_{\text {drift }} / u=0.12$.

Using these results, the probabilities of exceedance (19) of the IMO heeling levers are

$$
\begin{aligned}
& P\left(\text { heeling lever }>l_{\mathrm{w} 1}\right)=0.0067 \\
& P\left(\text { heeling lever }>l_{\mathrm{w} 2}\right)=0.0035
\end{aligned}
$$

in an ocean area where $u_{\text {mode }}=9.0 \mathrm{~m} / \mathrm{s}$.

\section{CONCLUSIONS}

Attention has been given to the long-term probabilistic wind loads on ships. They could form an integral part in the ship design procedure, for instance for the stability requirements. Ships may encounter rare but extreme wind loads. At sea the skipper will react and avoid severe conditions in wind and waves by adjusting the speed and course of the ship. Therefore severe wind effects may be less frequent than predicted by the concept of the statistical properties of the wind used in the numerical model. Reality may be on the safe side — as long as the ship is manoeuvrable.

\section{REFERENCES}

1 International Maritime Organisation (IMO). Code on Intact Stability for all Types of Ships Covered by IMO Instruments, 2002 (IMO Publications, London). 
2 Vassalos, D., Jasionowski, A. and Cichowicz, J. Weather criterion-questions and answers. In Proceedings of the 8th International Conference on The Stability of Ships and Ocean Vehicles, Escuela Técnica Superior de Ingenieros Navales, Madrid, Spain, 2003, pp. 695-707.

3 Blendermann, W. Probabilistic and spectral modelling of the wind loads on ships. Report 615, Naval Architecture Series, Technical University of Hamburg-Harburg, 2001, $53 \mathrm{pp}$.

4 Blendermann, W. Short-term and long-term statistics of the wind loads on ships. Schiffstechnik-Ship Technol., 2002, 49, 160-173.

5 Blendermann, W. Long-term wind loads on ships. Report 623, Naval Architecture Series, Technical University of Hamburg-Harburg, 2003, 29 pp.

6 Blendermann, W. Wind loading of ships - collected data from wind tunnel tests in uniform flow. Report 574, Institute of Naval Architecture, University of Hamburg, 1996, 62 pp.
7 Young, I. R. and Holland, G. J. Atlas of the Oceans: Wind ande Wave Climate, 1996 (Pergamon, Oxford).

8 Blendermann, W. Parameters of the long-term wind conditions above the oceans. Schiffstechnik-Ship Technol., 1998, 45, 99-104.

9 Van der Hoven, I. Power spectrum of horizontal wind speed in the frequency range from 0.0007 to 900 cycles per hour. J. Meteorology, 1957, 14, 160-164.

10 Davenport, A. G. The spectrum of horizontal gustiness near the ground in high winds. J. R. Met. Soc., 1961, 87, 194-211.

11 Garrat, J. R. Review of drag coefficients over oceans and continents. Monthly Weather Rev., 1977, 105, 915-929.

12 Miller, B. L. and Davies, M. E. Wind loading on offshore structures - a summary of wind tunnel studies. Report NMI R136, National Maritime Institute, Feltham, 1982, 68 pp.

13 Blendermann, W. Parameter identification of wind loads on ships. J. Wind Engng and Ind. Aerodynamics, 1993, 51, $339-351$. 